\title{
Will European reference networks benefit all EU patients with rare diseases?
}

\author{
Sally Ann Lynch ${ }^{1,2^{*}}$ and Jillian P Casey ${ }^{2}$ \\ 'National Rare Disease Office, Mater Hospital Dublin 7, Ireland \\ ${ }^{2}$ UCD Academic Centre of Rare Disease, School of Medicine and Medical Sciences, Belfield, Dublin 4, Ireland
}

Article Info

\section{Article Notes}

Received: May 19, 2016

Accepted: June 27, 2016

\section{*Correspondence:}

Dr. Sally Ann Lynch,

UCD Academic Centre of Rare Disease, School of Medicine

and Medical Sciences, Belfield, Dublin 4, Ireland

E-mail: sally.lynch@ucd.ie

(c) 2016 Lynch SA. This article is distributed under the terms of the Creative Commons Attribution 4.0 International License.

\section{Keywords}

Rare diseases

European reference networks

Equity

European Commission

European Union

\section{ABSTRACT}

European Reference Networks are being established across the EU with the aim of improving the care of patients with rare diseases. Recognising that experts are rare, ERNs are tasked with the aim of encouraging collaboration of experts across individual member states. Membership of an ERN is dependent on fulfilling criteria to allow one to be described as a centre of expertise. ERNs will produce guidelines through consensus and the development of EU wide registries should help to facilitate clinical trials. However, the ERN entry requirements are such that some member states will struggle to fulfil the criteria. Investment in trained staff for rare diseases has been poor in some countries risking the possibility that ERN membership may be restricted to a limited number of member states.

\section{Text}

It is well recognised that patients with rare diseases get lost in national health systems. The EU, has for the first time acknowledged the difficulties for patients with rare diseases through the 2009 Recommendation on the care of patients with rare diseases and the 2011 cross border directive, (Article $12 \& 13)^{1,2}$. These initiatives are a welcome attempt to reduce the diagnostic odyssey rare disease patients endure, as it recommends patients get access to and are managed in centres of expertise (CoEs). The 2009 recommendation states that Member states should "Identify appropriate centres of expertise throughout their national territory by the end of 2013, and consider supporting their creation" ${ }^{1}$. CoEs improve patient outcomes and are also cost effective for a number of reasons including; a) patients are more likely to get a diagnosis in a timely manner (avoiding unnecessary investigations), b) they spend less time as in-patients, c) drugs are administered efficaciously, and d) they are more likely to remain in education or employment ${ }^{3}$. The directive is a welcome initiative and should go some way in centralising care and improving outcomes.

The EU is in the midst of promoting the development of European reference networks (ERNs) in 22 rare disease thematic groups ${ }^{4,5}$. Each network has to have a minimum of 10 members from at least 8 member states. These members designated as CoEs, must meet operational criteria defined by the European Commission (EC) ${ }^{6}$, in addition to specific criteria dependent on the disorders covered by the network. A European reference network is a clinical network and must offer full multi-disciplinary care. Networks will be obliged 
to develop guidelines on management of individual rare disorders. Each network will undergo external evaluation to ensure they meet the operational criteria. The EC are providing support and core funding to administer the ERNs but the funding will not support local services.

The aim is for expertise to be disseminated throughout the EU via telemedicine and other eHealth tools. Occasionally it is envisaged that experts will travel. Lastly, patients from one member state can travel to another state for specialised care and their home country will pay the cost if there is no centre for expertise within their country. Whilst the EU directive does encourage individual member states to develop CoEs, many of the 28 member states will struggle to fulfil the ERN criteria. In particular, CoEs will need a full multidisciplinary team (specialised Medical and allied health professionals) in order to be designated as a CoE, prior to entering an ERN. Many member states have poorly developed services and limited access for training, in what is, a highly specialised area. Without fully functioning CoEs, some national centres will be in a position to enter only as an affiliated member of an ERN. Some EU countries are in debt to the European central bank and/or the International Monetary fund. Ironically, the EC issues reports on the fiscal spending policy of individual Member states \& highlight potential overspends in health amongst other sectors ${ }^{7}$. In response, recipient countries often focus on acute health care at the expense of non-acute health services and rare disease patients remain low priority. Despite the cross border directive stating that it will "help Member States with an insufficient number of patients with a particular medical condition or lacking technology or expertise to provide highly specialised services of high quality". It would help if the EC would mandate for individual member states to ringfence a proportion of their health care budget for rare diseases.

Despite this, there is no doubt that this directive should improve the care of many patients with rare diseases, as larger cohorts built through collaboration should improve expertise. It is also the first time many member states will have had to acknowledge that a) they have rare disease patients within their country and b) they have a responsibility to those patients.

The EU directive does state that the ERNs will "facilitate mobility of expertise, virtually or physically, and to develop, share and spread information, knowledge and best practice and to foster developments of the diagnosis and treatment of rare diseases, within and outside the network." In addition they will "help Member States with an insufficient number of patients with a particular medical condition or lacking technology or expertise to provide highly specialised services of high quality". However, there is no clear direction on how this is to work in practice. Education and support of those physicians from countries without nationally endorsed CoEs is part of the mission of ERNs. The European commission envisage that eHealth tools will fill this gap. Whilst the concept of telemedicine is attractive, it may not be practical or feasible for countries, who don't have the necessary multidisciplinary teams in place, to implement best practise or the ERN recommendationshence patients may be forced to travel to get access to the multi-disciplinary expertise or indeed access clinical trials and orphan drugs. There is also a risk that many of the poorer member states decide on a policy not to invest at a local level but to facilitate travel for able patients within their country. It may be more cost effective to pay for a few to travel to CoEs rather than investing in local services. It may only become more cost effective to invest locally if large numbers of patients travelled to CoEs regularly.

In addition, Orphan drugs need to be licensed by each individual EU country. Pharma are more inclined to enter larger countries that are "trial ready" with large cohorts of patients in established registries in a safer clinical setting. Smaller countries are less attractive and some pharma might consider against applying for a license where patient numbers are tiny. Patients know this, as do their clinicians. Most clinicians want the best for their patients, and, if that best is only available to their patients by travelling abroad, then this is what will be encouraged. Rare disease patients may continue to be neglected in some individual member states as there is nothing in the directive to obligate individual member states to improve outcomes locally other than giving patients the right to travel.

Clearly local investment is essential too for the following reasons:

1. Local experts are needed to make the diagnosis in the first place. Basic essential investigations and detailed phenotyping are required in order to identify the most appropriate CoE for each patient.

2. Many patients with rare diseases are infirm and travel is difficult.

3. Even if someone travels they need experts within their own country to manage acute and some chronic episodes.

4. Whilst, centres with larger patient numbers will be attractive to pharma to trial orphan drugs, they raise issues in terms of logistics for participating patients who are travelling from abroad to that centre. Without a smooth process offering ongoing dual care, the value of the expert opinion and/or treatment with orphan drugs could potentially be lost.

5. Many patients with rare autosomal recessive disorders come from endogamous populations that are a) vulnerable, b) do not engage readily with 
local health services and c) are extremely unlikely to travel to expert centres abroad eg Roma Gypsy, Irish Travellers etc ${ }^{8,9}$

6. A large and persistent association between education and health has been well-documented in many countries ${ }^{10}$. Those patients that do travel are more likely to be well educated and informed. There is a risk that those families from the poorer echelon's of our society will lose out.

7. Some ultra rare disorders may cluster in EU countries where there is no engagement with an ERN for that specific thematic disease group [because of poor national investment]. This would mean that the ERN would be missing a valuable resource in terms of patient number.

8. The social and educational aspects of rare disorders will require local experts as each individual member state has individual social care provisions.

Undoubtedly, collaboration across multiple EU countries will be essential in order to make any significant advancement in rare disease research - as each country is unlikely to have a sufficient number of patients to prove efficacy. However, recent published data originating from the European Commission www.ec.europa.eu/budget/fts: eCORDA (External Common Research Datawarehouse), shows that EU rare disease research funding over a 5 year period was not distributed equitably across the EU ${ }^{11}$. There is a risk that this new EU cross border directive may result in a widening of the inequity gap. The European Research Council strive to award grants based on scientific excellence alone, deliberately ignoring political borders that might interfere in judgement. Ultimately, grant funding is derived from taxpayers and we all want to maximise research output to get the best results for patients. ERNs are likely to be in a strong position to succeed in EU grant applications. It would be ideal if all 28 member states could strive to have at least one CoEs in each thematic group. In that way all EU patients should, in theory, have access to new therapies. However, no one is tasked to monitor this. If ERNS develop that are not inclusive of all member states, EU research funding might become limited to a selection of the EU population, inadvertently limiting the nationalities of the EU population being studied. Inclusion is a win win for both research outcomes and equity.
There are consequences from exclusion of specific groups of people from research. A recent lawsuit has been brought by the attorney general of Hawaii against two drug companies that failed to test a new drug across racial groups. The new drug showed reduced efficacy in East Asians and Pacific Islanders and the law-suit claims that the companies failed to disclose this issue ${ }^{12}$. Could EU personalised medicine research produce orphan drugs for a select section of the EU population and exclude large numbers of EU "persons"?

Without someone tasked with monitoring a) degree of inclusivity within ERNs and b) the delivery of service at national level throughout the EU countries, the cross border directive may result in a two tiered health system for patients with rare diseases.

The authors declare no Conflict of Interest.

\section{References}

1. http://download.eurordis.org/europlan/1_EU_Policy_Documents_ Rare_Diseases/2_FINAL_COUNCIL_RECOMMENDATIONS_ON_ RD_9\%20_JUNE_2009.pdf

2. http:/ / eur-lex.europa.eu / LexUriServ / LexUriServ. do?uri=OJ:L:2011:088:0045:0065:EN:PDF

3. http://www.eurordis.org/IMG/pdf/position-paper-EURORDIScentres-excellence-networksFeb08.pdf

4. http://ec.europa.eu/health/rare_diseases/european_reference networks/index_en.htm

5. Evangelista T, Hedley V, Atalaia A, Johnson M, Lynn S, Le Cam Y, et al. The context for the thematic grouping of rare diseases to facilitate the establishment of European Reference Networks. Orphanet J Rare Dis. 2016 Feb 24; 11: 17. doi: 10.1186/s13023-016-0398-y. PMID:26911987

6. ht t p://ec.europa.eu/health/ern/docs/ern delegateddecision_20140310_en.pdf

7. http://ec.europa.eu/economy_finance/publications/eeeb/pdf/ eb011_en.pdf

8. Sepkowitz KA. Health of the world's Roma population. Lancet. 2006 May 27; 367(9524): 1707-8.

9. Green A, Lynch SA. Health of the world's Roma population.Lancet. 2006 Aug 12; 368(9535): 575.

10. Cutler DM, Lleras-Muney A. Education and Health http://www.npc. umich.edu/publications/policy_briefs/brief9/

11. Lynch SA, Borg I. Wide disparity of clinical genetics services and EU rare disease research funding across Europe. J Community Genet. 2016 Apr; 7(2): 119-26. doi: 10.1007/s12687-015-0256-y. Epub 2015 Nov 4.PMID:26536881

12. Hayden EC. Nov 2015 http://www.nature.com/news/racial-biascontinues-to-haunt-nih-grants-1.18807 